\title{
Non-Neoplastic, Non-Molar Trophoblastic Disorder
}

National Cancer Institute

\section{Source}

National Cancer Institute. Non-Neoplastic, Non-Molar Trophoblastic Disorder. NCI

Thesaurus. Code C40184.

A category of non-neoplastic trophoblastic disorders that affect the placenta. It includes the exaggerated placental site and placental site nodule or plaque. 